\title{
Silêncio! Não desperte os inocentes: sexualidade, gênero e educação sexual a partir da concepção de educadores
}

\author{
Ana Paula Leivar BRANCALEONI ${ }^{1}$ \\ Rosemary Rodrigues de OLIVEIRA ${ }^{2}$
}

\section{Introdução}

A sexualidade, independentemente de sua potencialidade reprodutiva, relaciona-se com a busca do prazer. Trata-se de um aspecto fundamental no processo de construção da identidade e se manifesta, de formas diferentes, desde o nascimento até a morte, abarcando dimensôes biológicas, psíquicas e socioculturais. Assim, desde as primeiras vivências de prazer, nos contatos do bebê com o adulto (frequentemente a mãe), a sexualidade é construída, pelo sujeito, a partir das possibilidades culturalmente estabelecidas, sendo, portanto, um processo permanentemente permeado por valores, crenças e de padróes socialmente estabelecidos de feminino e masculino.

Ressalta-se, neste contexto, o ambiente escolar como um espaço permeado pela sexualidade. A escola é um lugar de informação e formação, no qual estão

1 UNESP - Universidade Estadual Paulista. Faculdade de Ciências Agrárias e Veterinárias - Departamento de Economia Rural. Jaboticabal - SP - Brasil. 14884900. UNESP - Universidade Estadual Paulista. Faculdade de Ciências e Letras Programa de Pós-Graduação em Educação Sexual. Araraquara - SP - Brasil. 14800901 - anapaulabrancaleoni@gmail.com

2 UNESP - Universidade Estadual Paulista. Faculdade de Ciências Agrárias e Veterinárias - Departamento de Economia Rural. Jaboticabal - SP - Brasil. 14884900 - oliveirose@fcav.unesp.br 
Silêncio! Não desperte os inocentes: sexualidade, gênero e educação sexual a partir da concepção de educadores

presentes todas as áreas do conhecimento, de forma ordenada, que constituem um "curriculum", um percurso a ser percorrido pelo aluno, bem como um conjunto de relaçóes sociais e humanas. Mais do que salas, prédio, alunos e professores, uma escola é fruto das relaçóes que nela se dão, participando da constituição da identidade dos indivíduos que dela participam (SEFFNER, 1998).

Como afirmam Ribeiro, Souza e Souza (2004, p.110), entende-se a o processo pedagógico como:

Um sistema em que se articulam práticas discursivas implicadas em relaçóes de poder e significação que, ao construir conhecimentos, desejos e valores, se encontram implicadas na constituição de identidades/subjetividades.

Assim, além dos saberes clássicos e tradicionais, a escola constrói e transmite outros saberes. Educar para a saúde, além de ser responsabilidade dos serviços de saúde, é também dever da escola por ser uma instituição capaz de transformarse em um espaço de promoçáo a uma vida saudável, conforme indicam os Parâmetros Curriculares Nacionais (PCN) (BRASIL, 1998). Contudo, como aponta Bento (2011), hegemonicamente a escola participa da constituição e reprodução do "heteroterrorismo", afirmando uma dada norma acerca da sexualidade e do gênero, através de regras, leis, interdiçóes e puniçóes. Assim, aqueles que não se enquadram nesses padróes estabelecidos de normalidade são desumanizados e, inclusive, excluídos da perspectiva dos direitos humanos fundamentais.

Destaca-se que, especialmente com a atuação dos movimentos sociais LGBTs (Lésbicas, Gays, Bissexuais, Travestis e Transexuais), novos temas e problemas surgem todos os dias e não faltam pressóes para que a escola "se encarregue" deles. Assim, a problemática da sexualidade e do gênero é um dos temas emergentes que fica parado na porta das escolas, pedindo para entrar e lá ser discutido. Isso provoca temores em muitos professores, pois no bojo do tema "sexualidade" costuma vir uma série de assuntos polêmicos e constrangedores: sexo, drogas, homossexualidade, promiscuidade, doença, agonia, morte, pecado, discriminação, masculino e feminino, entre outros (SEFFNER, 1998). Devido a esses temores associados e explicados, em parte, pela dificuldade da comunidade escolar em lidar com temas táo permeados por valores. Os professores, muitas vezes, acabam por disseminar uma visão reducionista dos assuntos referentes ao sexo e à sexualidade. Estes comumente são apresentados como "perigosos", intimamente articulados a Doenças Sexualmente Transmissíveis (DSTs) e à gravidez indesejada, pautando-se, portanto, em uma visão higienista que reduz o corpo aos conceitos de assepsia, controle e prevenção, sendo o estudo do mesmo 
delegado ao campo da Biologia (REIS; RIBEIRO, 2005). Como afirma Bento (2011, p.555):

A escola, que se apresenta como uma instituição incapaz de lidar com a diferença e a pluralidade, funciona como uma das principais guardiãs das normas de gênero e produtoras da heterossexualidade. Para os casos em que as crianças são levadas a deixar a escola por náo suportarem o ambiente hostil, é limitador falarmos em evasão.

Bento (2011) destaca toda uma dinâmica que se processa no ambiente escolar, que atua na expulsão do diferente, materializando o inconfesso "desejo de eliminar" aqueles que rompem com as normas estabelecidas, que afrontam o binarismo de gênero, por meio do qual se compreende e estabelece-se uma relação lógica, que não pode ser questionada, de congruência entre sexo biológico, gênero e orientação sexual. Ao normalizar essa configuração, patologizam-se todos aqueles que não se enquadram na mesma e que, portanto, não são desejados, também, no ambiente escolar. Dessa maneira, dizer que os que rompem com os padróes evadem frequentemente da escola é encobrir, com tecido espesso, o heteroterrorismo que pauta o cotidiano da escola e suas práticas pedagógicas.

Entre as normalizaçóes presentes da escola, conforme Ribeiro, Souza e Souza (2004), destaca-se a crença na "assexualidade e inocência das crianças menores", nesse sentido tratam de temas referentes à sexualidade e ao gênero, junto às mesmas, seria incitá-las à prática do sexo e à promiscuidade. Como afirmam os autores:

A primeira questáo torna visível a preocupação dos professores com a existência de uma série/idade 'certa' para tratar desses objetos, pois o discurso presente nas escolas e em outras instâncias sociais apontam para a criança como inocente e assexuada. Portanto, caso elas venham a falar sobre sexualidade com crianças, estaráo despertando-as precocemente para o assunto, uma vez que o conhecimento poderá estimulá-las a ter experiências sexuais (entendimento da sexualidade como ato sexual). (RIBEIRO; SOUZA; SOUZA, 2004, p.122).

Castro, Abramovay e Silva (2004), ao destacarem as dificuldades dos educadores para trabalhar a sexualidade e o gênero de forma explícita e pedagogicamente planejada, referem que os assuntos vêm sendo tratados principalmente como "[...] um conteúdo restrito ao campo disciplinar da biologia, reificando-se o corpo como aparato reprodutivo, o que molda a compreensão a respeito da saúde e da doença." (CASTRO; ABRAMOVAY; SILVA, 2004, p.38) e assinalam que a maneira como a sexualidade é abordada na escola geralmente não contempla os anseios e as curiosidades das crianças e adolescentes. Isto sucede 
Silêncio! Não desperte os inocentes: sexualidade, gênero e educação sexual a partir da concepção de educadores

porque o enfoque é centralizado apenas no corpo biológico, não incluindo, portanto, os outros aspectos da sexualidade.

Esse 'jogo de empurra entre os professores' destaca o quanto a sexualidade e ao gênero são questôes espinhosas. Mesmo com a redução da questão à reprodução e prevenção de doenças e gravidez, a tarefa de desenvolver o trabalho é o 'mico' que, por falta de condição de escolha, sobra com aqueles que não podem oficialmente declinar. Vale salientar, contudo, que não é exclusividade da disciplina de ciências biológicas abordar temas relacionados à sexualidade, tendo em vista que os Parâmetros Curriculares Nacionais para Orientação Sexual (BRASIL, 1998) se baseiam no princípio que os mesmos devem ser tratados transversalmente, visto ser um elemento fundamental para a vida dos sujeitos em sociedade. Trata-se de um tema amplo e polêmico, multidimensional, demarcado pela história, pela cultura e pela configuração social. Assim, o documento oficial indica que o mesmo pode e deve ser tratado em momentos e disciplinas distintas, ou seja, deve "ser incorporado nas áreas já existentes e no trabalho educativo da escola" (BRASIL, 1998, p.17), pois "[...] sua complexidade faz com que nenhuma das áreas, isoladamente, seja suficiente para explicá-los; ao contrário, a problemática dos temas transversais atravessa os diferentes campos do conhecimento." (BRASIL, 1998, p.26). No decorrer do processo de escolarização da criança e do adolescente, sabe-se que, na escola, é competência das disciplinas curriculares Ciências e Biologia tratar conteúdos como doenças sexualmente transmissíveis, fisiologia e reprodução humanas no Ensino Fundamental e no Ensino Médio respectivamente, nos quais é especialmente difícil determinar a fronteira que separa os conceitos científicos das ciências naturais de um discurso moralizante em relaçáo ao sexo, para crianças e adolescentes. Desse modo, a ideia de transversalidade da sexualidade, veiculada nos $\mathrm{PCN}$, não coincide com a concepção generalizada de que a escola e os educadores, mais especificamente, têm sobre esse tema.

Diante do exposto, assume-se o princípio de que possibilitar que a escola discuta a sexualidade em seu caráter multidimensional, implica também que a formação do professor contemple esse aspecto. Isto porque esta discussão depende, dentre outros fatores, de docentes que se sintam capazes de abordar e problematizar não apenas aspectos associados ao corpo biológico, a saber: DSTs, anatomia e fisiologia do sistema reprodutor masculino e feminino, mas, sobretudo aspectos sociais, culturais, éticos, filosóficos, entre outros, pois são estes aspectos que, em conjunto com a biologia, darão sentido à sexualidade e auxiliarão os professores a desenvolverem esta temática em sala de aula junto aos estudantes, na busca de possibilitar a estes atores sociais uma vivência responsável de sua sexualidade. Portanto, entende-se que o professor é o ator/ autor social a quem cabe o papel de, na escola, auxiliar o estudante a subjetivar 
o conhecimento, transformá-lo em algo pessoal através da reflexão sobre suas curiosidades e angústias referentes à sexualidade. Desta forma, conhecendo seu corpo, sentimentos e valores, possam viver a sexualidade de maneira mais plena, visto que os jovens necessitam de espaços em que possam questionar, desenvolver a capacidade de tomar decisóes, comunicá-las aos outros, lidar com os conflitos e defender as suas opiniôes, mesmo que (ou principalmente se) essas sejam contrárias às opiniôes dos outros.

Embora a formação do professor seja apontada, pela literatura pertinente, como essencial no processo de discussão e construção de saberes sobre sexualidade, Silva e Megid Neto (2006), ao realizarem levantamento sobre o estado da arte da produção de cursos de pós-graduação brasileiros sobre formação de professores para o trabalho com sexualidade nos vários níveis escolares, analisou 65 teses e dissertaçóes defendidas no período de 1977 a 2001, constatando que a formação inicial de professores, nessa temática, foi abordada somente em quatro produçóes e, para a ação pedagógica no processo de formaçáo inicial, é relatada a utilizaçáo de oficinas, sem, no entanto, informar como foram operacionalizadas.

Ratificamos que a escola é instituição em que são veiculados os valores hegemônicos, que reproduzem relaçôes de dominação também no que se refere ao gênero e à nossa relação com a sexualidade. Contudo, a mesma também pode vir a se constituir espaço de problematizaçáo e ruptura, na medida em oportunizar a reflexão e clarificação de valores, normas e sentimentos. O educador exerce uma função fundamental, seja no processo de manutenção dos valores hegemônicos e da legitimação de processos de dominação, seja na possível ruptura com o instituído. Assim, faz-se essencial conhecer as compreensões dos professores acerca de temas relativos à sexualidade, mesmo porque estas conduzem suas práticas no cotidiano educacional.

\section{Objetivos}

Diante do exposto, o presente trabalho tem por objetivo analisar a compreensão de um grupo de educadores de uma Escola Pública acerca de temas relativos à sexualidade e ao gênero, especialmente no que se refere: a) forma como compreendem a sexualidade e o gênero; b) as relaçóes estabelecidas entre sexualidade e idade; c) o trabalho com o tema no cotidiano escolar; d) a educação sexual na escola.

\section{Trajetória metodológica}

\section{- A aproximaçáo com o campo}

O presente trabalho foi desenvolvido em uma escola de Ensino Fundamental da rede estadual de Ensino de uma cidade do interior do estado de Sáo Paulo. A 
Silêncio! Não desperte os inocentes: sexualidade, gênero e educação sexual a partir da concepção de educadores

equipe educativa procurou um projeto de extensão universitária, com a demanda explícita de um trabalho a ser desenvolvido com uma das quintas-séries que "tinha muitos alunos avançados para sua idade" no que se referia à sexualidade. Afirmavam não saber como trabalhar com esses alunos que vinham de famílias promíscuas e expostos, por conta das condiçóes financeiras e familiares (famílias desestruturadas), a estímulos impróprios para a faixa etária. Assim, desejavam trabalhos que ensinassem formas adequadas de pensar e se comportar aos estudantes em questão.

Ao se iniciarem oficinas com o referido grupo, a equipe da universidade também passou a ser percebida como agentes que "estimulavam o sexo". Diante disso, salientou-se a necessidade de conhecer as compreensóes desses educadores sobre sexualidade, gênero e educação sexual de modo a subsidiar um trabalho mais amplo com os diferentes agentes da escola. Assim, propôsse a pesquisa, através da qual, chegaram-se aos resultados apresentados neste trabalho.

\section{- Abordagem de pesquisa adotada}

Pautou-se em uma metodologia qualitativa, em que se considera o pesquisador como o principal instrumento de investigação, sendo essencial o contato direto e prolongado com o campo. Nessa perspectiva, a principal atenção centra-se no processo e náo em um produto matematicamente sistematizado (ALVES, 1991). Desta forma, proporciona-se um avanço na interpretação dos resultados, na medida em oportuniza um maior aprofundamento na compreensão do objeto de estudo (TRIVIÑOS, 1992).

Como afirmam Bodgan e Biklen (1997) o pesquisador, nessa perspectiva busca compreender como as pessoas que vivenciam a situação estudada a significam, que valor dão a essa situação, bem como a dinâmica interna do ambiente.

\section{- Processo de coleta de dados}

Foi utilizada como instrumentos de coleta, especialmente a observaçáo participante. O Observador participante, cuja influência no universo estudado não é descartada, pode participar do mesmo de diferentes formas, dependendo do grau de participação. No caso do presente trabalho, assumiu-se a condiçáo de observador como participante (HAMMERSLEY; ATIKISON, 1992; LUDKE; ANDRÉ, 1986). Foram também realizados grupos temáticos de discussão com os educadores. As observaçóes e falas nos grupos foram sistematicamente registradas em diário de campo. A coleta de dados ocorreu ao longo de um semestre com frequência semanal. 


\section{- A análise dos resultados}

Inicialmente foi realizada uma leitura completa e minuciosa dos registros de diário de campo e dos registros das falas dos participantes dos grupos temáticos de modo a imergir no material. Progressivamente foram sendo identificadas unidades temáticas (BARDIN, 1977). Essas unidades referem-se à identificação de um tema, que, neste caso, tratava-se dos aspectos centrais, do conjunto de registros realizados. O tema, como unidade de registro, é geralmente utilizado no estudo de valores, crenças e tendências (BARDIN, 1977) e pode ser recortado em enunciados e em proposiçóes portadoras de significaçóes.

Após a identificação e destaque de todos os temas encontrados, as pesquisadoras realizaram discussóes a fim de que os temas fossem classificados e agregados em categorias temáticas, sendo destacadas as respostas consideradas como mais significativas e que melhor ilustram as constataçôes apresentadas.

\section{Resultados e discussão}

Após a análise dos dados, chegou-se aos seguintes eixos de discussão: a compreensão dos professores sobre sexualidade e gênero; o trabalho com o tema no cotidiano escolar; a educação sexual no cotidiano escolar; o trabalho com o tema sexualidade e gênero com alunos da quinta série.

\section{- Compreensóes dos professores sobre sexualidade e gênero}

Constatou-se que os educadores apresentavam uma compreensão hegemônica que reduzia a sexualidade à pratica do sexo. Referiam-se frequentemente às crianças que já haviam "despertado" para a sexualidade como aquelas que já tinham praticado ou desejavam praticar sexo. Os demais estudantes, por ainda não desejarem experimentar o ato sexual, em si, eram significadas ainda como "assexuados". Como ilustra a fala de uma das professoras de Ciências:

Então, tem uns que não têm essa coisa de sexualidade ainda, são crianças mesmo ainda não despertaram para a sexualidade. Mas outros têm experiência mais que devia, já têm relação sexual e tudo.

Dessa forma, previam estágios "normais" de desenvolvimento, em que a questáo da sexualidade deveria aparecer apenas na adolescência e como algo que precisava ser educado para que a mesma acontecesse dentro dos limites da normalidade. Nesse sentido, destaca-se a fala de um professor que ocupava a função de coordenação pedagógica:

Porque quando em casa há um ambiente mais sadio, a questäo da sexualidade vai aparecer mesmo na adolescência, quando os hormônios mudam e o corpo muda. Mas com a desestruturaçâo familiar e o estimulo que recebem, a gente tem que 
Silêncio! Não desperte os inocentes: sexualidade, gênero e educação sexual a partir da concepção de educadores

enfrentar isso mais cedo do que devia. Dai vem a educação sexual. Eles precisam saber das consequências, do que é correto e o que náo é bom.

Há desta forma, uma naturalização da sexualidade em detrimento de seus aspectos sociais, históricos e até mesmo de construção do próprio sujeito. Resgatam-se, aqui, as afirmaçóes de Ribeiro, Souza e Souza (2004) ao destacarem os processos de regulação da escola por meio dos dispositivos discursivos que marcam, como seres desviantes, aqueles que não atendem aos comportamentos e atitudes previstos, para uma sexualidade inscrita como normal.

Desta forma, os educadores firmavam-se em modelos heteronormativos, em que as configuraçóes identitárias distintas eram compreendidas como defeituosas. Apresentavam, dessa forma, uma visão biologizante e patologizante acerca da sexualidade e das relaçóes de gênero.

Constatava-se, assim, uma redução da sexualidade e do gênero ao corpo reprodutivo, retirando o caráter existencial da mesma e convertendo-a em questão médica (CASTRO, ABRAMOVAY; SILVA, 2004). A respeito da medicalização da sexualidade, as falas de educadores, abaixo transcritas são ilustrativas:

A gente, aqui na escola, sempre traz um médico para dar as explicaçôes, informaçôes e orientaçôes sobre sexualidade para os aluno.

Quando a gente percebe que tem alguma coisa de anormal com a criança, a gente chama os pais aconselhando para que procurem um médico ou um psicólogo.

Outra questão que merece destaque é a concepção binária de gênero como organizadora do cotidiano escolar. Partia-se do entendimento de que as meninas são aquelas que possuem vulva e vagina e que naturalmente, a menos que um problema ocorra, teráo interesse sexual por meninos, assim como os meninos são aqueles que possuem pênis e que naturalmente se interessam por meninas. A fala do professor de matemática é bastante ilustrativa do script de papéis e comportamentos previstos para os alunos, a partir do seu genital de nascimento, segundo ele:

Porque você nota assim [...] Meninos e meninas são bem diferentes. É natural dos meninos eles gostam mais de coisas assim competitivas, violentas. Já as meninas são mais vaidosas, começam até pensar nessa coisa de namoro antes, né? É bem diferente, porque homens e mulheres são diferentes, né? Tem mais ou menos um jeito de agir das meninas e dos meninos.

Assim, meninos percebidos como efeminados e meninas entendidas como masculinizadas eram significados como anormais. Portanto, quanto mais se rompem com o padrão binário, mas são alocados como "seres adjetos", marcados como portadores de transtornos (BENTO, 2011). Nos discursos, por diversas 
vezes, compareciam sobre a designação de "problemas". A fala do professor coordenador exemplifica esse sentido:

A gente tem problema assim [...] Por exemplo, meninos que se comportam de forma mais feminina em sala de aula. A gente fica pensando [...] chama pai e mão prá conversar, ou não [...] é difícil. Os colegas também tiram sarro. Então, é difícil lidar.

Bento (2011) chama-nos a atenção para a gravidade da patologização das identidades que acaba por legitimar e autorizar a sentença e punição daqueles que rompem com as normas. A autora inscreve a patologização das sexualidades e identidades divergentes das normas como "o heteroterrorismo em pleno processo de funcionamento". Como afirma a autora: "[...] os divergentes sexuais e de gênero só poderão existir em espaços apropriados, nos compêndios do saber médico e nos espaços confessionais das clínicas. Lá os encontraremos, todos hierarquizados, classificados e especificados.” (BENTO, 2011, p.557).

\section{- O trabalho com o tema no cotidiano escolar}

Observou-se também a dificuldade dos professores para trabalhar com o tema no cotidiano escolar. Evitavam o tema por náo se sentirem preparados. No jogo de empurra, os professores de biologia eram entendidos como aqueles efetivamente responsáveis por desenvolver trabalhos com o tema "pois fazia parte dos conteúdos de sua disciplina”. Como afirmou o professor que exercia a função de coordenador pedagógico:

Porque esse é um tema difícil envolve muita coisa, é complicado trabalhar. $\dot{E}$ difícil eu pedir para um professor de matemática, por exemplo, trabalhar o tema, não tem formação, não sabe como. Quem tem mais condição de trabalhar o tema é o professor de ciências e biologia porque é da formação dele. É o professor de ciências e biologia que é responsável por trabalhar reprodução. Então é difícil [...]

Estas compreensões distanciam-se das preconizações traçadas pelos Parâmetros Curriculares Nacionais (1998), contudo são consonantes a dados encontrados em outras pesquisas já desenvolvidas (REIS; RIBEIRO, 2005; RIBEIRO; SOUZA; SOUZA, 2004). Assim, também entre os educares estudados, identificou-se a lacuna entre o posto pelos Parâmetros e aquilo que se sentem capazes de trabalhar e desenvolver.

Inclusive, a questão da necessidade do trabalho com a questão no cotidiano escolar compareceu como algo que causava ansiedade e desconforto. Temiam que ocorressem situaçóes, diante das quais, não soubessem se posicionar o que permeava, inclusive, a relação estabelecida com os pais. As dúvidas eram muitas: 
Silêncio! Não desperte os inocentes: sexualidade, gênero e educação sexual a partir da concepção de educadores

o que deveriam responder para os pais, quando questionados? Quais seriam as posturas mais adequadas? A professora de Biologia afirmou:

É que é assim, acontecem muitas coisas na escola. Muitas vezes a gente não sabe o que fazer. Faz o que acha certo, mas fica sempre a dúvida. Será que deveria agir assim mesmo.

Vale relatar um acontecimento bastante ilustrativo desse "não saber agir diante dos acorridos". Um garoto, identificado na escola como portador de necessidades especiais, furtou uma revista pornográfica em uma banca nas proximidades da instituiçáo. Durante o período que estava na escola foi pego com a revista e confessou o furto. Segundo fala do coordenador, posteriormente ao ocorrido, náo sabiam como agir no momento. Diante da dúvida, decidiram por acionar a Ronda Escolar e os pais do aluno. Os pais e o aluno seguiram na viatura da polícia até a Unidade da Ronda escolar para conversa e esclarecimentos sobre o ocorrido. Entre os educadores o assombro não dizia respeito ao furto em si, mas sim ao material do furto: "a revista pornográfica", especialmente por ser um "aluno deficiente". O fato de ser um adolescente "deficiente mental" e demonstrar desejo/interesse sexual comparecia como algo bastante desconcertante. Este foi apenas um, entre tantos outros casos observados, em que a perplexidade tomava conta, diante de um ocorrido que pedia respostas e ações por parte dos adultos educadores.

Frente às inseguranças dos educadores identificavam-se duas posturas predominantes: aqueles que buscavam negar a questão da sexualidade e que, inclusive, assumiam posturas mais agressivas diante dos que propunham a discussáo do tema e aqueles que solicitavam receitas e manuais de conduta. As falas abaixo ilustram essas duas posturas:

Eu evito falar no assunto e dar brecha para isso. Assim a gente evita muita coisa.

A gente tem que agir, mas sabendo direitinho como fazer. Então, assim [...] nesse caso tem que fazer assim, nesse outro assado [...] quando acontece isso, quando acontece aquilo [...] assim, o que precisa fazer em cada situaçâo. Eu queria saber exatamente a conduta correta.

Chama-se a atenção para o fato de que a principal demanda da escola era para que agíssemos nas situaçóes que identificavam como sendo difíceis, ou que a atuação da universidade fosse diretamente com os alunos, de modo que não precisassem, eles próprios, trabalhar com o tema junto aos estudantes. Desta forma, quanto mais longe estivesse o "mico" melhor. Frente a todo desconforto, o maior desejo era que um agente externo se encarregasse do fardo representado pelo trabalho e pela lida com as questóes de sexualidade e gênero. 
Esses posicionamentos nos fazem refletir o quanto a formação para o trabalho com a sexualidade no cotidiano escolar foi preterida, seja no seu caráter inicial ou por propostas de formação continuada. Essas carências também foram destacadas por Silva e Megid Neto (2006). Como afirma Seffner (2011, p.570):

Abordar temas relativos a gênero e sexualidade exige nas escolas a presença de professores com formação específica, feita geralmente na modalidade de formaçáo continuada ou em serviço. Esses temas aparecem de modo imprevisto na sala de aula, e em princípio qualquer professor deve estar preparado para uma abordagem inicial. Mas um trabalho continuado deve ser desenvolvido por docentes com qualificaçáo dispostos a enfrentar essa questáo.

\section{- O papel da escola na educaçáo sexual}

Os educadores questionavam em que medida a educação sexual seria uma tarefa da escola. Em suas compreensóes, a mesma seria de responsabilidade da família. Nessa medida, atribuíam a causa dos comportamentos que julgavam inadequados, do ponto de vista da expressão da sexualidade e do gênero, à configuração familiar daquela criança e/ou jovem que se portava daquela maneira. Conforme afirmavam: "tem coisas que precisam ser ensinadas em casa", "Se não vem de casa porque é a escola que tem que se responsabilizar". A fala de uma das professoras é ilustrativa:

Então, o problema é que agora querem que a escola se responsabilize por coisas que não são dela. E a questão da sexualidade é uma delas. Porque isso é função da família. É que a condição das famílias hoje, você já viu. Então acaba sobrando prá escola o que náo é dela. A gente tem que ensinar conteúdo e os pais educarem os filhos para a sexualidade, não é com a gente.

Patto (1999) discute a complexa relação estabelecida entre escola e família, especialmente quando se trata de famílias de baixa renda. Discute o desencontro entre ambas e ressalta o olhar preconceituoso e estereotipado acerca da família, ao localizá-la como desestruturada, partindo do pressuposto de que existe a estrutura correta, sendo a mesma única. Dessa forma, acaba-se responsabilizando unicamente a família por questốes que são de caráter compartilhado.

Identifica-se, portanto, por parte dos educadores, uma concepção bastante normatizadora, sustentada na moral da família mononuclear heterossexual. O papel das instituiçóes, desta forma, seria de adequar os mais novos aos parâmetros corretos, já estabelecidos.

É importante problematizar, ainda, a concepção de família apresentada pelos educadores ao classificarem as configuraçôes familiares dos alunos em "famílias estruturadas" e "famílias desestruturadas", sendo compreendida como 
Silêncio! Não desperte os inocentes: sexualidade, gênero e educação sexual a partir da concepção de educadores

"estruturada e correta" aquela composta por pai, mãe e filhos (desse mesmo pai) que vivem sob o mesmo teto. A fala da professora de Geografia é ilustrativa:

O problema é que hoje tá tudo uma bagunça. Os irmãos são de vários pais, a família não tem estrutura, não há referência.

Seffner (2011) salienta a importância da discussão e desconstrução das crenças que posicionam a família monuclear como padrão de normalidade, na medida em que os alunos não são mais oriundos de famílias homogêneas, mas provêm de uma grande diversidade de configuraçôes familiares. Portanto, o autor propóe, inclusive, que não se fale mais de "família", mas sim "famílias" que, em seu plural, representa melhor os vários arranjos e modalidades de cuidado familiar às crianças e jovens.

Pondera-se, ainda, que a classificação das famílias em "estruturadas e desestruturadas" participam do processo de estigmatização e patologização de identidades, sendo a "desestrutura da família" utilizada como causa inicial dos "desvios" e justificativa para o processo de exclusão e eliminação dos diferentes.

Portanto, no que se refere ao papel da escola na promoção da educaçáo sexual, constata-se uma falta de clareza e o forte desejo que desonerar-se da responsabilidade nesse processo. Essa postura vai de encontro às consideraçóes de Seffner (2011) que preconiza que o professor é um adulto de referência para a criança e para o jovem, com especial destaque para as questóes referentes à sexualidade e ao gênero, o que implica na responsabilidade do mesmo e da escola como um todo, no trabalho com os temas.

\section{- A educaçáo sexual no cotidiano escolar}

Também foi recorrente a representação de que ao se tratar de temas relativos à sexualidade incita-se à prática precoce do sexo. Assim, os posicionamentos em relação à existência de um projeto, que trazia por objetivo trabalhar com questóes relativas à sexualidade e ao gênero junto a pré-adolescentes e adolescentes, eram bastante ambíguos. Ao mesmo tempo em que referidos pelos educadores como um trabalho importante, que lhes "trazia até certo alívio", na medida em que se sentiam desresponsabilizados do trabalho com o tema no cotidiano escolar, também acusavam o mesmo estimular as crianças/jovens a pensamentos e desejos de "sexo precocemente", o que aumentaria as dificuldades que enfrentavam, com essas questóes, no cotidiano da escola. Portanto, ter alguém que tratasse do tema, na escola, de modo que os próprios educadores não precisassem fazê-lo, era desejado e bem aceito, desde que o trabalho promovesse a permanência do afastamento e do silêncio pretendidos para o cotidiano escolar. Portanto, os membros do projeto deviriam compor o conluio para a garantia do enclausuramento dos temas 
no universo do obsceno, do que não pode ser dito, do que não tem nome, ou como frequentemente ouvia-se “aquelas coisas". Mais uma vez identifica-se o movimento para que as questões relativas à sexualidade e ao gênero ficassem para além dos portóes da escola, como se isso fosse possível. Contudo, apesar do esforço, elas penetravam pelos poros e fios da tecitura desse cotidiano. As falas abaixo são representativas desse desejo de silenciamento e afastamento da questão:

Porque é assim [...] Sem a gente falar nada já tem muitos que são adiantados, pensando em coisas que náo devia para a idade deles. Imagina se a gente começar a falar do assunto [...] se começa a falar dessas coisas [...] ai sim, se estimular ai que ninguém segura.

Se a gente pensar, são temas muitos pesados, a sexualidade é um tema muito pesado e ainda é muito cedo para eles saberem de certas coisas, para despertarem para o sexo. Quando mais tempo ficarem sem ter contato com essas coisas é melhor. Então eu fico pensando até que ponto o projeto de educação sexual desperta para questóes que não são deles. Tem coisa que talvez seja melhor não mexer.

Essas compreensóes vão ao encontro dos achados de Ribeiro, Souza e Souza (2004) que, em estudo realizado há mais de uma década, constataram a crença dos professores da existência de uma série/idade correta para tratar de temas referentes à sexualidade e ao gênero, na medida em que trabalhar esses assuntos poderia estimular precocemente os alunos às experiências sexuais - leiase à prática do sexo. Depara-se, portanto, com a permanência e a manutenção dessa associação entre o trabalho com temas referentes à sexualidade/gênero e o estímulo à prática do sexo, assim como a condutas que rompem com os padróes heteronormativos.

Outra questão contatada foi a ideia de que a orientação sexual e identidade de gênero podem ser influenciadas e, até mesmo determinadas, pelo conteúdo e condução das propostas de educação sexual na escola. Assim, dependendo da condução dos trabalhos, os mesmos poderiam ser responsáveis por estimular a homossexualidade e/ou transexualidade ao "banalizar-se esses assuntos". O professor de matemática referiu:

Porque a molecada segue o grupo e é muito influenciável também [...] por aquilo que ouvem, pelos professores, pela forma como as coisas são trabalhadas na escola e em casa também. Por exemplo, pode ter moda de ser gay sem serem mesmo, só porque é moda no grupo. E foi banalizado [...]

Dessa forma, muitas vezes as oficinas sobre sexualidade desenvolvidas com os alunos eram significadas como incitadoras da atenção e desejo pelo sexo, assim como portas para que os "desvios" fossem autorizados. Qualquer situação que 
Silêncio! Não desperte os inocentes: sexualidade, gênero e educação sexual a partir da concepção de educadores

envolvesse questóes relativas à sexualidade era atribuída como sendo decorrente à participação dos alunos no projeto, fosse de qualquer natureza, até mesmo aquelas características de brincadeiras entre jovens e/ou crianças. Cita-se, como exemplo, o incômodo causado na professora de ciências quando um aluno, ao formular uma questão, usou a palavra "pinto" ao invés de "pênis". O ocorrido foi compreendido como uma falta de respeito para com a professora, decorrente do estímulo recebido através das oficinas.

Destarte, o desejo explícito era de que o trabalho de educação sexual tivesse uma configuração normalizadora, pautada nos pressupostos heteronormativos, engendrando o processo heteroterrorista, conforme apresentado por Bento (2011).

Assim, as diferenças são significadas como defeitos não havendo um processo educativo de promoção do respeito à diversidade sexual e de gênero, mais do que isso, nem se previa essa perspectiva naquilo que a equipe educativa compreendia por educação sexual. Destacam-se aqui as considerações de Louro (2001), ao discutir a questão de uma pedagogia capaz de abarcar as diferenças sexuais e de gênero, sem que as mesmas precisem ser enquadradas e reduzidas a grupos identitários e/ou guetos. Segundo a autora:

Uma tal pedagogia sugere o questionamento, a desnaturalizaçáo e a incerteza como estratégias fortes e criativas para pensar qualquer dimensão da existência. A dúvida deixa de ser desconfortável e noviça para se tornar estimulante e produtiva. As questóes insolúveis não cessam as discussôes, mas, em vez disso, sugerem a busca de outras perspectivas, incitam a formulação de outras perguntas, provocam o posicionamento a partir de outro lugar. (LOURO, 2001, p.555).

\section{- O trabalho com o tema sexualidade com alunos da quinta série}

Compreendiam que havia uma idade certa, não apenas para a prática sexual, mas para qualquer manifestação de prazer e desejo na relação das pessoas com os seus corpos. Assim, caso o desenvolvimento ocorresse normalmente o "aflorar para a sexualidade" deveria ocorrer apenas na adolescência e dentro de alguns parâmetros, conforme também constataram Ribeiro, Souza e Souza (2004). Representavam os alunos do último ano do Ensino Fundamental, como aqueles que estavam ingressando na adolescência e que, portanto, naturalmente estariam despertando para o "sexo". Justificavam esse momento de "despertar para a sexualidade" pelas mudanças hormonais e corporais pelas quais os jovens passavam. Mais uma vez identifica-se a redução da sexualidade ao corpo biológico reprodutivo (CASTRO; ABRAMOVAY; SILVA, 2004). A fala da professora de biologia é bastante ilustrativa: 
Na quinta série eles são ainda muito crianças. É claro que tem aqueles que estão avançados para a idade, o que é um problema. Mas a maioria deles não [...] São crianças mesmo. Imagina ainda não tem nem peitinho [...] Os meninos nem penugem na cara.

Assim, quando se referiam aos alunos do $5^{\circ}$ ano, avaliavam que alguns eram "avançados", pois possuíam informaçóes de temas relativos à sexualidade antes do tempo adequado para isso. Portanto, os educadores entendiam que esses alunos transitavam por "lugares" em que ainda não deveriam estar. Atribuíam esse "adiantamento de etapas" à configuração familiar dessas crianças. Suas atitudes e inquietaçôes certamente eram decorrentes da forma de (des)organização da família em que estavam inseridos. Entendiam que a promiscuidade era uma possível característica das mesmas.

Isso porque, segundo os educadores pesquisados, caso aquelas crianças náo fossem expostas a esses conhecimentos precocemente, seriam inocentes como devem ser todas elas.

Dessa forma, os alunos eram classificados em dois polos: os avançados e os inocentes. Os trabalhos de educação sexual deveriam ser desenvolvidos só com os "avançados", visto que são "aqueles que precisam desse tipo de trabalho". Comparece, portanto, mais uma vez a representação da educação sexual como estratégia de contenção.

\section{Conclusões}

Constatou-se que os educadores apresentavam uma compreensão hegemônica que reduzia sexualidade à pratica do sexo. Apresentavam, dessa forma, uma visão biologizante e patologizante acerca da mesma. Observou-se também a dificuldade dos professores para trabalhar com o tema no cotidiano escolar. Evitavam o tema por não se sentirem preparados. Temiam que ocorressem situaçôes, diante das quais, não soubessem se posicionar o que permeava, inclusive, a relação estabelecida com os pais.

A demanda dos educadores era que a tarefa de educação sexual fosse substituída por agentes externos à escola (universitários, família, médicos). Os educadores questionavam, inclusive, em que medida o trabalho com questóes relativas à sexualidade e ao gênero seria uma tarefa da escola, visto que compreendiam que a responsabilidade seria da família. Também foi recorrente a representação de que tratar de temas relativos à sexualidade incita a prática precoce do sexo entre os alunos. Dessa forma, compreendiam que havia uma idade certa, não apenas para a prática sexual, mas para qualquer manifestação de prazer e desejo na relação com os seus corpos. 
Silêncio! Não desperte os inocentes: sexualidade, gênero e educação sexual a partir da concepção de educadores

Avaliavam que alguns alunos eram "avançados", pois possuíam informações de temas relativos à sexualidade antes do tempo adequado para isso, o que certamente decorria da configuraçáo da família (desestruturada) em que estavam inseridos. Caso não fossem expostos a esses conhecimentos precocemente, seriam inocentes como devem ser as crianças. Em suas falas a questão da sexualidade no cotidiano escolar comparecia como "problemas que deveriam ser sanados", dessa forma, algo sempre significado como ruim. Assim, as atividades de orientaçáo sexual eram necessárias para as salas difíceis. Portanto, falar sobre sexo objetivaria conter a prática sexual e normalizar condutas.

O convite explícito era para o silenciamento das questóes referentes à sexualidade e ao gênero, mas que, contudo invadiam o cotidiano e assombravam os educadores.

\section{REFERÊNCIAS}

ALVES, A. J. O planejamento das pesquisas qualitativas em educaçáo. Cadernos de Pesquisa, São Paulo, n. 77, p. 53-61, maio 1991.

BARDIN, L. Análise de conteúdo. Lisboa: 70, 1977.

BENTO, B. Na escola se aprende que a diferença faz a diferença. Revista Estudos Feministas, Florianópolis, v.19, n.2, p.549-559, ago. 2011. Disponível em: <http://www. scielo.br/pdf/ref/v19n2/v19n2a16.pdf>. Acesso em: 30 ago. 2015.

BODGAN, R.; BIKLEN, S. Investigaçáo qualitativa em educaçáo. Porto: Ed. Porto, 1997.

BRASIL. Secretaria de Educação Fundamental. Parâmetros Curriculares Nacionais: terceiro e quarto ciclos: apresentação dos temas transversais. Brasília, 1998.

CASTRO, M. G.; ABRAMOVAY, M.; SILVA, L. B. da. Juventudes e sexualidade. Brasília: UNESCOl, 2004.

HAMMERSLEY, M.; ATIKINSON, P. Etnography: principles in practice. London: Routledge, 1992.

LOURO, G. L. Teoria queer: uma política pós-identitária para a educação. Revista Estudos Feministas, Florianópolis, v.9, n.2, p.541-553, 2001. Disponível em: <http://www.scielo.br/ pdf/ref/v9n2/8639.pdf >. Acesso em: 30 ago. 2015.

LUDKE, M.; ANDRÉ, M. E. D. A. A pesquisa em educaçáo: abordagens qualitativas. São Paulo: EPU, 1986.

PATTO, M. H. S. A produçáo do fracasso escolar: histórias de submissão e rebeldia. São Paulo: Casa do Psicólogo, 1999.

REIS, G. V.; RIBEIRO, P. R. M. Sexualidade e educaçẫo escolar: algumas reflexôes sobre orientação sexual na escola. In: BORTOLOZZI, A. C.; MAIA, A. F. (Org.). Sexualidade e infância. Bauru: FC/UNESP: CECEMCA, 2005. p. 34-45. (Série Cadernos Cecemca, v.1).

RIBEIRO, P. R. C.; SOUZA, N. G. S. de; SOUZA, D. O. Sexualidade na sala de aula: pedagogias escolares de professoras das séries iniciais do Ensino Fundamental. Revista 
Estudos Feministas, Florianópolis, v.12, n.1, p.109-129, abr. 2004. Disponível em: <http:// www.scielo.br/pdf/ref/v12n1/21694.pdf >. Acesso em: 30 ago. 2015.

SEFFNER, F. Um bocado de sexo, pouco giz, quase nada de apagador e muitas provas: cenas escolares envolvendo questóes de gênero e sexualidade. Revista Estudos Feministas, Florianópolis, v.19, n.2, p.561-572, ago. 2011. Disponível em: <http://www.scielo.br/pdf/ ref/v19n2/v19n2a17.pdf >. Acesso em: 30 ago. 2015.

. Aids \& escola. In: MEYER, D. E. E. (Org.). Saúde e sexualidade na escola. Porto Alegre: Mediação, 1998. p.125-143.

SILVA, R. C. P. da; MEGID NETO, J. Formação de professores e educadores para abordagem da educação sexual na escola: o que mostram as pesquisas. Ciência e Educaçáo, Bauru, v.12, n.2, p.185-197, 2006.

TRIVIÑOS, A. N. S. Introduçáo à pesquisa em Ciências Sociais: a pesquisa qualitativa em educação. São Paulo: Atlas, 1992. 
Silêncio! Não desperte os inocentes: sexualidade, gênero e educação sexual a partir da concepção de educadores

\title{
Resumo
}

Silêncio! Não desperte os inocentes: sexualidade, gênero e educação sexual a partir da concepção de educadores

A escola é um espaço permeado pela sexualidade. Contudo, vários estudos constatam dificuldades para lidar com o tema no cotidiano escolar. A educação sexual também é tema de debates e polêmicas envolvendo a equipe escolar, pais e pesquisadores. Este artigo propóe discutir as concepçóes de sexualidade e gênero de educadores de uma escola pública do interior de Sáo Paulo. Nesta pesquisa utilizou-se uma abordagem qualitativa. Os instrumentos de coleta de dados foram: observação participante e grupos temáticos com educadores. Os dados foram sistematicamente registrados em diário de campo e foram analisados pelo método de análise de conteúdos. Constatou-se que os educadores não se sentem preparados e nem desejam trabalhar com o tema. Atribuem à família a responsabilidade da educação sexual. Compreendem que a adolescência é a faixa etária correta para que a sexualidade desperte. Entendem que as crianças são inocentes porque não se interessam por sexo. Salienta-se a redução da sexualidade ao sexo e da reprodução dos padrốes heteronormativos. Portanto, todos os alunos que não se enquadram nos padrôes esperados sáo vistos como anormais. A principal causa atribuída à "anormalidade" desses estudantes é a configuração familiar em que os mesmos estão inseridos.

Palavras-chave: Sexualidade. Gênero. Educação sexual.

\begin{abstract}
Silence! You do not arouse the innocent: sexuality, gender and education in understanding educators

The school is a place permeated with sexuality. However, several studies Realize difficulties to deal with the subject in everyday school life. Sex education is also the subject of debates and controversies involving school staff, parents and researchers. This article aims to discuss the conceptions of sexuality and gender of teachers of a public school in São Paulo. In this research we used a qualitative approach. Data collection instruments were: participant observation and focus groups with educators. Data were systematically recorded in a field diary. and analyzed by the content analysis method. It was found that educators feel unprepared and did not wish to work with the theme. Attach to family responsibility of sex education. They understand that adolescence is the correct age to awaken sexuality. They understand that children are innocent because they are not interested in sex. It emphasizes the reduction of sexuality to sex and reproduction of heteronormative standards. Therefore, all students who do not meet the expected standards are seen as abnormal. The main cause attributed to the "abnormality" of these students is the family setting in which they are inserted.
\end{abstract}

Keywords: Sexuality. Gender. Sex education. 